\title{
Outcome of Teenage Pregnancy
}

\author{
Soubhagya Talawar ${ }^{1}$, Venkatesh $\mathrm{G}^{2}$ \\ ${ }^{1}$ Department of obstetrics and gynecology, SDM Medical College, India \\ ${ }^{2}$ Department of pediatrics,, SDM Medical College India
}

\begin{abstract}
Teenage pregnancy is a health risk for mother and fetus. It is associated with high maternal, fetal and neonatal morbidity and mortality. This study aims to examine teenage pregnancy, study risks associated with teenage pregnancy and adverse birth outcome.
\end{abstract}

Keywords: Adverse birth outcome, case control study, teenage pregnancy.

\section{Introduction}

Adolescence is a period of transition from childhood to adulthood. According to WHO the period of adolescence extends from 11-19 years. Pregnancy during this period is called teenage pregnancy ${ }^{1,6}$.

Teenage pregnancy is one of the most important social and public health problem all over the world with varying prevalence rate $\mathrm{e}^{1,2}$. Teenage pregnancy represents a high risk group in reproductive terms because of the double burden of reproduction and growth ${ }^{3}$. Teenagers make up more than one billion i.e., nearly one fifth of the world population ${ }^{4}$. The aim of this study was to compare several obstetric characteristics and outcomes of teenage women to that of controls aging 20-24years.

\section{Material And Methods}

It is a prospective case control study, wherein 100cases of teenage pregnancy (13-19years) were compared with 100cases of controls (20-24years) for maternal and fetal outcome admitted in SDM Medical college, India, during the period from 1/1/11 to 31/12/12.Data was collected with information covering maternal risk factors and obstetric outcome. Adequate antenatal care (ANC) was defined by the following criteria viz., (1) $\geq$ antenatal checkups (2) receipt of 2 doses of tetanus toxoid and iron and folic acid supplementation. Exclusion criteria included are mothers with major illness existing from pre-pregnant state which could adversely affected the outcome of pregnancy, viz., heart disease, bronchial asthma, hypertension, diabetes mellitus and hypothyroidism. Results were analyzed by GraphpadInstat3 software program. P value less than 0.05 was taken as statistically significant.

\section{Results}

Incidence of teenage pregnancy is $10.4 \%$. Incidence of teenage primigravida was $94 \%$. Incidence of teenage multigravida was $6 \%$ out of which previous normal deliveries were $5 \%$ and previous caesarean was $1 \%$. Pregnancy in the age group of 13-16years was $1 \%$ and between 17-19years was 99\%.Mean age of teenagers was 18.5years in cases and 22.3years in controls and it was found to be statistically significant( $t$ value 30.63 and $p$ value $<0.001$ and $\mathrm{SD} \pm 0.6$ ).

\subsection{Complications:}

There was increased incidence of anemia, preeclampsia, preterm delivery and PROM compared to control group. Table-1

Table-1: Complications of teenage pregnancy

\begin{tabular}{|l|l|l|l|l|}
\hline Complications & Cases $(\%)$ & Controls (\%) & P value & Statistical significance \\
\hline Anemia & 30 & 14 & 0.009 & S \\
\hline Preterm delivery & 14 & 2 & 0.0029 & S \\
\hline Hydramnios & 1 & 0 & 1 & NS \\
\hline PROM & 10 & 2 & 0.05 & S \\
\hline Breech presentation & 2 & 5 & 0.07 & NS \\
\hline Malposition & 1 & 0 & 1 & NS \\
\hline Preeclampsia & 26 & 11 & 0.001 & S \\
\hline Eclampsia & 6 & 2 & 0.27 & NS \\
\hline PPROM & 1 & 0 & 1 & NS \\
\hline Multiple pregnancy & 0 & 1 & 1 & NS \\
\hline APH & 2 & 2 & 1 & NS \\
\hline Congenital anomaly & 1 & 0 & 1 & NS \\
\hline
\end{tabular}

S-significant, NS-not significant 


\subsection{Indications of caesarean section:}

Although the most common indication of caesarean section in our study is Cephalopelvic disproportion followed by fetal distress. The incidence of caesarean section between two groups is not statistically significant. Incidence of caesarean section and forceps delivery were similar in both the groups and is not statistically significant. Table-2 The incidence of low birth weight and prematurity is high in study group compared to control group. The causes for low birth weight are mainly eclampsia, preeclampsia and anemia in our study. Table-3.

Table-2: Indications for cesarean section:

\begin{tabular}{|l|l|l|l|l|}
\hline Indications & Cases (\%) & Controls (\%) & P value & $\begin{array}{l}\text { Statistical } \\
\text { Significance }\end{array}$ \\
\hline CPD & 10 & 8 & 0.0857 & NS \\
\hline Fetal distress & 4 & 3 & 0.9 & NS \\
\hline Breech & 2 & 2 & 1 & NS \\
\hline Failure to progress & 1 & 1 & 1 & NS \\
\hline Placenta previa & 1 & 0 & 1 & NS \\
\hline Malpositions & 1 & 0 & 1 & NS \\
\hline Cord prolapsed & 1 & 0 & 1 & NS \\
\hline Failed induction & 1 & 1 & 1 & NS \\
\hline $\begin{array}{c}\text { Threatened scar } \\
\text { rupture }\end{array}$ & 0 & 2 & 0.49 & NS \\
\hline Total & 21 & 17 & & \\
\hline
\end{tabular}

Table-3: Fetal and neonatal outcome:

\begin{tabular}{|l|l|l|l|l|}
\hline Complications & Cases(\%) & Controls(\%) & P value & $\begin{array}{l}\text { Statistical } \\
\text { significance }\end{array}$ \\
\hline Perinatal mortality & 4 & 2 & 0.68 & NS \\
\hline Fresh still birth & 1 & 1 & 1 & NS \\
\hline Macerated still birth & 1 & 0 & 1 & NS \\
\hline Neonatal death & 2 & 1 & 1 & NS \\
\hline Low birth weight & 27 & 16 & 0.05 & S \\
\hline Congenital anomalies & 1 & 0 & 1 & NS \\
\hline Prematurity & 14 & 2 & 0.0029 & S \\
\hline
\end{tabular}

\section{Discussion}

Incidence of teenage pregnancy is $10.4 \%$ in the present study whereas other studies showed the incidence ranging from $8.3-23.4 \%{ }^{1,6,9,11,14}$. In our study the mean age of teenage gravida is $18.5 y e a r s$ and that of controls is 22.3 years. In the present study we did not find any significant difference in registration between cases and controls. We did not come across any unmarried teenage mother in our study. It is common practice for unmarried mothers to go for termination of pregnancy ${ }^{1,5}$. No abortion was found in any age group.

Incidence of anemia, preeclampsia, eclampsia and premature rupture of membranes were found to be significantly higher than the controls in the present study. This is in accordance previous studies $^{1,4,5,7,8,9,10,13,14}$, and contrast other showed no difference in incidence of anemia ${ }^{6,9}$. Gestational diabetes mellitus was less common in younger women ${ }^{8,9,13}$.

Regarding the mode of delivery, incidence of cesarean section and forceps delivery were similar in both groups. This is in accordance to previous studies ${ }^{6,7,9,10}$. Some authors have reported increased operative deliveries $^{1,3,5,7,9,11}$; whereas other have shown less incidence of cesarean section ${ }^{3,4,7,11,13,15}$. This could be due to higher proportion of smaller babies in that age group. Opinion on modes of delivery by operative interventions in teenage pregnancy differed widely. Some authors have reported a higher rate of instrumental deliveries in the case of teenage pregnancies. The possible explanation could be underdevelopment of pelvis in teenage mothers. Others have shown no significant difference in the mode of delivery between two groups ${ }^{3,5,6,7,8,15}$. The common indication for caesarean section in our study is Cephalopelvic disproportion. This is in accordance with previous studies $^{13}$. Next common indication is fetal distress. Incidence of preterm delivery is statistically significant in our study; this is in accordance with previous studies $1,2,4,5,7,8,10,12,13,14,15$. Others have shown no significant statistical significance in preterm delivery in two groups ${ }^{6,9,11,12}$. Immaturity of the uterine and cervical blood 
supply may predispose teenage mothers to subclinical infection, an increase in prostaglandin production, and a consequent increase in the incidence of preterm delivery ${ }^{1,8,9}$.

Many studies have reflected poor perinatal outcome in the form of preterm delivery, low birth weight and increased perinatal mortality $1,2,3,4,5,10,13,14,15$ which is in accordance with the present one; whereas others found no statistical significance between two groups ${ }^{6,8,9,11,12}$.

\section{Limitations}

The primary limitation of the study was that, it is a hospital-based study and it may not truly reflect the prevailing situation in a community. Another limitation of the study was that adverse perinatal outcome of teenage pregnancy could have been confounded by the different sociodemographic characteristics in the two groups.

\section{Conclusion}

India is fast approaching to be the most populous country in the world, and teenage pregnancy is likely to aggravate the problem. We should take steps not only to improve the reproductive outcome but also decrease the incidence of teenage pregnancy by increasing public awareness, ensuring female education and enforcing marriage law. Teenage pregnancy needs to be tackled as a priority to ease the burden of socioeconomic and health problems.

\section{References}

[2] Gordon C S Smith, Jill P Pell. Teenage pregnancy and risk of adverse perinatal outcomes associated with first and second births: population based retrospective cohort study. BMJ 2001Sept; 323:1-5.

[3] PriankaMukhopadhyay, R.N.Chaudhuri, Bhaskar Paul. Hospital-based Perinatal Outcomes and Complications in Teenage Pregnancy in India. J Health PopulNutr2010 Oct; 28(5):494-500.

[4] Pun KD, Chauhan M. Outcomes of Adolescent Pregnancy at Kathmandu University Hospital, Dhulikhel Hospital. Kathmandu Univ Med J 2011;33(1):50-3.

[5] SupananChairaj, KasornTosang, SuvannaAsavapiriyanont, UraiwanChotigeat. Outcome of Teenage Pregnancy in Rajavithi Hospital.J Med Assoc Thai 2010;93(1):1-8.

[6] Suwal A. Obstetric and Perinatal Outcome of Teenage Pregnancy. J Nepal Health Res Counc 2012 Jan;10(20):52-6.

[7] VorapongPhupong, KengSuebnukarn. Obstetric Outcome in Nulliparous Young Adolescents.Southeast Asian J Trop Med Public Health 2007 Jan; 38(1):141-145.

[8] M.C. Jolly, N.Sebire,J.Harris, S.Robinson, L.Regan. Obstetric Risks of Pregnancy in Women Less Than $18 \quad$ Years Old.Obstetric Gynecol 2000;96(6):962-6.

[9] SabryM.Hammad, RedaQ.Al-Enazi. Does teenage pregnancy affect obstetric outcomes?.The Egyptian Journal Of Community Medicine.2010 July;26(3):25-35.

[10] ChutatipTantayakom, JaparathPrechapanich. Risk of Low Birth Weight Infants from Adolescent Mothers: Review Case Study in SirirajHospital.ThaiJournal of Obstetrics and Gynecology April 2008;16(2):103-106.

[11] Nusrat Shah, Dileep Kumar Rohra, SamiaShuja, Nagina Fatima Liaqat, Nazir Ahmad Solangi, Kelash Kumar et al. Comparison of obstetric outcome among teenage and non-teenage mothers from three tertiary care hospitals of Sindh, Pakistan. J Pak Med Assococt 2011;61(10):963-967.

[12] Nathalie A, Fleming, XiaowenTu, Amanda Y.Black. Improved Obstetrical Outcomes for Adolescents in a CommunityBased Outreach Program: A Matched Cohort Study. J ObstetGynaecol Can２012;34(12):1134-1140.

[13] CandanIltemir DUVAN, NilgunOzturk TURHAN, IlknurInegol GUMUS, Hilal YUVACI, Elif GOZDEMIR. Adolescent Pregnancies: Maternal and Fetal Outcomes. The New Journal of Medicine 2010;27:113-116.

[14] Bhalerao AR, Desai SV, Dastur NA, Daftary SN. Outcome of teenage pregnancy.J Postgrad Med 1990;36:136-9.

[15] Siddhartha Yadav, DilipChoudhary, Narayan K.C.,Rajesh Kumar Mandal, Achyut Sharma, Siddharth Singh Chauhan et al. Adverse Reproductive Outcomes Associated With Teenage Pregnancy. McGill Journal of Medicine 2008;11(2): 141-1 